\title{
Environmental aspects and renewable energy sources in the production of construction aggregate
}

\author{
Izabela Skrzypczak ${ }^{1, *}$, Wanda Kokoszka $^{1}$, Lidia Buda-Ożóg ${ }^{1}$, Janusz Kogut ${ }^{2}$, \\ Marta Słowik ${ }^{3}$ \\ ${ }^{1}$ Rzeszow University of Technology, Faculty of Civil, Environmental Engineering and Architecture, \\ Rzeszow, Poland \\ ${ }^{2}$ Cracow University of Technology, Faculty of Civil Engineering, Krakow, Poland \\ ${ }^{3}$ Lublin University of Technology, Faculty of Civil Engineering and Architecture, Lublin, Poland
}

\begin{abstract}
The main activity of open pit mining of aggregates are aggregates' exploitation of natural mineral deposits and its modification in order to obtain high-quality aggregates. The development of aggregate production is conditioned by a number of factors. The most important are: documented material resources, mining and manufacturing capabilities, the need of environmental protection (environmental aspects), the subordination of the plan of spatial development, formal and legal issues, as well as economic and financial aspects. While identifying and assessing the environmental impacts of manufacturing aggregates one may distinguish those environmental aspects that have or may have the greatest magnitude of the impact on the environment as a result of industrial activities. Manufacturers producing aggregates located in the areas covered by the special environmental protection require extra diligence in the conduct of mining activities for preservation of natural resources. The article discusses some main environmental aspects of the production of construction aggregates on the example of one of the largest producers of this material in Subcarpathian province of Poland. Environmental protection in production of aggregates may refer to four aspects: the use of natural resources, having excluded land from agriculture and forestry, land reclamation after exploitation, and use of energy from renewable energy sources. The economic and environmental impact of production volume of aggregates is evaluated by the index information capacity method and the method of graphs.
\end{abstract}

\section{Introduction}

As a result of the open pit mining activities, exploitation natural aggregates in building and road construction, several components the natural environment such as soil, terrain, water relations are violated. During the service and production processes a lot of energy is used, as well as the waste and pollutant emission to the environment is generated.

\footnotetext{
*Corresponding author: izas@prz.edu.pl
} 
Companies which produce aggregates distinguish those environmental aspects that may have the greatest magnitude of the impact on the environment as a result of their activities [1-5]. Manufacturers having produced aggregates located in the areas covered by the special environmental protection require extra diligence in the conduct of mining activities for the preservation of natural resources [4,5]. The article discusses some main environmental aspects of the production of construction aggregates on the example of one of the largest producers of this material in Subcarpathian province of Poland. The economic and environmental impact of production volume of aggregates is evaluated by the index information capacity method and the method of graphs.

\section{Environmental issues in the production of construction aggregate}

The most important restriction in access to resources of natural aggregates is the protection of living nature and a landscape. The strictest form of protection are national parks and wildlife sanctuaries. Protecting wildlife habitats of wild animals and birds is a priority, hence the exploitation of minerals in these areas is impossible, while in landscape parks there are limitations of mining activities. One of the most restrictive forms related to the investment expansion, is an European network of protected areas Natura 2000, which aims to preserve biodiversity by protecting ecosystems. The largest wildlife refuge - the Bieszczady mountains cover about 111,519.5 ha, and appears here as both the area of protection of birds and habitats.

Some restrictions to conducting mining activities, connecting with Natura 2000, may prevent access to a significant amount of mineral resources, and in the case of exploited deposits a need of abandoning exploitation. Every area of the Natura 2000 regardless of whether it has been approved or is only planned is protected by law. The rules prohibit, until approved of the area by the European Commission from carrying out any activity that may aggravate the condition of natural habitats included in such area [7].

Development of the industry of natural aggregates is limited by increasing the size of protected areas. This fact prevents and/or restricts access to the production of aggregates and the environmental factor rises to the primary factor. Natura 2000 law has covered large area, which is a natural resource base of raw materials suitable for the production of aggregates, so the environmental issues significantly reduce the amount of deposits for possible production of aggregates.

\subsection{Environmental objectives and targets on the example of the Subcarpathian manufacturer of aggregates}

The main environmental issues are discussed on the example of the company, which introduced of classified-aggregates in south-eastern Poland based on natural aggregate. Currently, the basic activity of the company is the mining of natural raw materials, later modification and manufacturing of construction aggregates, according to the European standards. In 2015, this company produced 5.1 million tons of aggregates, which have been used in construction and road building, which is about $5 \%$ of national production in Poland [7]. The primary activity of the company is determined by the environmental issues, which have or may have the greatest magnitude of impact on the environment as a result of production. The influence of particular parameter on the environment is performed by the analysis of environmental performance factors. Table 1 presents each factor in relation to the production volume for the years 2013-15. 
Table 1. Environmental performance factors [8]

\begin{tabular}{|c|c|c|c|c|}
\hline Factor & Type & 2013 & 2014 & 2015 \\
\hline \multirow{2}{*}{ Waste } & Hazardous [t] & 13.191 & 12.864 & 16.793 \\
\cline { 2 - 5 } & Non-hazardous [t] & 370.983 & 116.657 & 81.087 \\
\hline Energy efficiency & $\begin{array}{c}\text { Electric energy } \\
\text { consumption [MWh] }\end{array}$ & 11776 & 11308 & 12704 \\
\hline Material efficiency & Fuel consumption [m $\left.{ }^{3}\right]$ & 2035.5 & 2153.6 & 2244 \\
\hline Biodiversity & Industrial areas [ha] & 220.9 & 216.8 & 205.1 \\
\hline Air pollution emissions & $\left(\mathrm{SO}_{2}, \mathrm{NO}_{\mathrm{x}}, \mathrm{PM}\right)[\mathrm{t}]$ & 129.38 & 161.60 & 143.82 \\
\hline
\end{tabular}

It should be emphasized that the volume of waste generated in all organizational units of the company will not exceed the amount of permitted by decisions of the organs of state administration. Referring to Table 1, one may concluded that the change of production technology contributed to a reduction of electricity and fuel consumption. Introduction of high-performance excavator and crushers, which have replaced reduction in consumption of electricity in 2014. The rise in unit consumption of electricity per ton of production in 2015, is the result of increased demand for grits, which is associated with work of energyintensive crushers.

Until 2013, reduction in unit fuel consumption is recorded. This is due to the use in the extraction of aggregates excavators with increased efficiency. In addition, changing of technology works is continued through the use of open-pit dump truck, replacing the bulldozers. As a result of these actions the fuel consumption per 1 ton of aggregates production is reduced in relation to 2013 in all company units. It reached (calculated in thousands. liters of fuel per ton of aggregate) 0.45 in 2010, 0.43 in 2011 and 0.42 in 2012 [3]. The increase in fuel consumption per ton of production in 2014-15 is related to the more difficult deposits (deeper located) and the extension of transport routes between mines and processing units. The consequence of higher fuel consumption is an increase in the unit rate of emissions of pollution to the air.

It should be stressed, that the company using natural resources, pays maintenance fees to the National Fund for Environmental Protection and Water Management. Also, local authorities get the fees for using the environment (including emissions, dust and gas, and water consumption fees). In 2015, the total funds granted for the environmental protection amounted to 2.88 million PLN (including $97.1 \%$ service charge due to the minerals extraction and $2.9 \%$ fee for emissions of pollutants and water consumption). In 2015 unit fee for 1 ton of aggregate production decreased due to the reduction of operational charges.

In 1997-2001, in the frame of reclamation of gravel pits, the company constructed the water reservoir having dammed the Wisłoka river with the weir. The capacity of the reservoir is about 6 million cubic meters of water. This reservoir is currently in use also for leisure purposes, and enables the production of renewable energy in the hydroelectric power plant. However, despite this investment the company did not apply to the aggregate production other renewable energy sources.

\subsection{Economic and environmental factors and the production volume}

The economic and environmental impact of production volume of aggregates is evaluated by the index information capacity method and the method of graphs.

Index information capacity method is based on the basic mathematical formulas with combinatorics and correlation coefficients of the analysed features. In contrast, the method of graphs is based on the correlation matrix, shows the relationship of selected parameters. The following factors are used for the analysis (see Table 2): 


$\begin{array}{lll}\mathrm{Y} & \text { - aggregates production } & \left(10^{6} \mathrm{t}\right), \\ \mathrm{X} 1 & - \text { hazardous waste } & (\mathrm{Mg}), \\ \mathrm{X} 2 & - \text { other waste } & (\mathrm{Mg}), \\ \mathrm{X} 3 & - \text { electric energy consumption } & (\mathrm{MWh}), \\ \mathrm{X} 4 & - \text { environmental fees } & (\mathrm{PLN} / \mathrm{t}), \\ \mathrm{X} 5 & - \text { index of production efficiency } & \left(\mathrm{m}^{2} / \mathrm{t}\right) .\end{array}$

Table 2. Production of construction aggregates factors in subsequent years [8]

\begin{tabular}{|c|c|c|c|c|c|c|}
\hline Year & Y & X1 & X2 & X3 & X4 & X5 \\
\hline $\mathbf{2 0 0 6}$ & 4.696 & 13885 & 151.100 & 10485.5 & 0.550 & 0.460 \\
\hline $\mathbf{2 0 0 7}$ & 4.800 & 14456 & 160.300 & 10635.2 & 0.560 & 0.450 \\
\hline $\mathbf{2 0 0 8}$ & 5.349 & 15680 & 190.500 & 12335.8 & 0.530 & 0.450 \\
\hline $\mathbf{2 0 0 9}$ & 5.168 & 16776 & 193.700 & 11607.5 & 0.490 & 0.440 \\
\hline $\mathbf{2 0 1 0}$ & 6.972 & 13359 & 193.700 & 11968.8 & 0.520 & 0.400 \\
\hline $\mathbf{2 0 1 1}$ & 5.443 & 16270 & 235.240 & 13177.4 & 0.489 & 0.388 \\
\hline $\mathbf{2 0 1 2}$ & 5.170 & 13992 & 179.983 & 11264.7 & 0.518 & 0.454 \\
\hline $\mathbf{2 0 1 3}$ & 4.915 & 13191 & 170.983 & 11776.0 & 0.523 & 0.449 \\
\hline $\mathbf{2 0 1 4}$ & 5.031 & 12864 & 116.657 & 11308.0 & 0.578 & 0.431 \\
\hline $\mathbf{2 0 1 5}$ & 5.099 & 16793 & 81.087 & 12704.0 & 0.556 & 0.402 \\
\hline
\end{tabular}

The method of graphs analysis [9] - is a graphical method of expressing the relationship between the explanatory variables. It involves searching for a group of variables correlated with each other and to find the variables that are not correlated with other explanatory variables. The next step is to select from this group, variables which are strongly correlated with the response variable and then use them in the model. The model also includes all uncorrelated variables but related to the dependent variable. The correlation matrix for the data from the Table 2 is shown in Table 3.

Table 3. The correlation matrix

\begin{tabular}{|c|c|c|c|c|c|c|}
\hline & $\mathbf{Y}$ & $\mathbf{X 1}$ & $\mathbf{X 2}$ & $\mathbf{X 3}$ & $\mathbf{X 4}$ & $\mathbf{X 5}$ \\
\hline $\mathbf{Y}$ & 1 & -0.099 & 0.368 & $\mathbf{0 . 3 8 5}$ & -0.339 & $\mathbf{- 0 . 5 8 9}$ \\
\hline $\mathbf{X 1}$ & -0.099 & 1 & 0.104 & $\mathbf{0 . 5 6 6}$ & $\mathbf{- 0 . 4 2 8}$ & -0.340 \\
\hline $\mathbf{X 2}$ & 0.368 & 0.104 & 1 & 0.223 & $\mathbf{- 0 . 8 2 2}$ & -0.079 \\
\hline $\mathbf{X 3}$ & 0.385 & $\mathbf{0 . 5 6 6}$ & 0.223 & 1 & $\mathbf{- 0 . 4 5 7}$ & $\mathbf{- 0 . 7 6 5}$ \\
\hline X4 & -0.339 & $\mathbf{- 0 . 4 2 8}$ & $\mathbf{- 0 . 8 2 2}$ & $\mathbf{- 0 . 4 5 7}$ & 1 & 0.244 \\
\hline X5 & -0.589 & -0.340 & -0.079 & $\mathbf{- 0 . 7 6 5}$ & 0.244 & 1 \\
\hline
\end{tabular}

Subsequent variable that is hazardous waste (X1), non-hazardous waste (X2), consumption of electric energy. (X3) and environmental fee (X4) show a weak correlation with the variable $\mathrm{Y}$ (the production of aggregates). Based on the correlation matrix it may be concluded that the production of aggregates is influenced primarily by the index of production efficiency (significant correlative relationship) and energy consumption (moderate correlation).

In order to determine which of the variables has a decisive influence on the production volume of aggregates inference based on the method of graphs has been conducted (Figure 1). Schematic relationship between variables is developed. The relationship is based on the correlation matrix taking into account these variables, for which the value of the correlation coefficient is greater than 0.40 (i.e. the average correlation). Determinants are shown in red in Figure 1. 


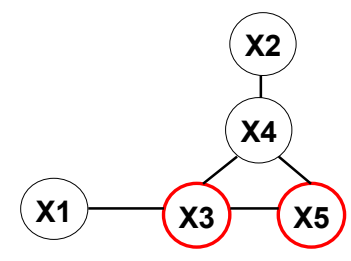

Fig.1. Graphs method

Based on the analysis of graphs it may be observed that the revised explanatory variables can be merged into two groups. With the first group, the main characteristics that influence the volume of aggregates production is a factor of efficiency of the production (variable X5). It is strongly correlated with the endogenous variable (the volume of aggregate production) than the variable X3 (energy consumption). While the variable X1 (hazardous waste), as virtually insulated top, also affects the parameter determining the volume of aggregates production.

Index information capacity method [10-13] consists in determining the indicators of individual and integral to the individual carriers. The basic problem of the method application is to calculate all the possible $1,2, \ldots, k-1, k$ - elements combinations of potential explanatory variables of the so-called information capacity of individual indicators. The total number of combinations that may enter the model for the analyzed case is equal to:

$$
K=2^{m}-1
$$

where $m$ is the number of exogenous variables, $m=5$, so the number of combinations is equal to 31 .

Subsequently, the capacity of each individual media presented in the specified combinations according to the formula (2):

$$
\boldsymbol{h}_{j i}=\frac{r_{i}^{2}}{1+\sum_{i=1}^{n}\left|r_{i j}\right|}
$$

where: $r_{i}$ - the correlation coefficient parameter $i$ with respect to the characteristics of the explanatory $y$

$r_{i j}$ - the correlation coefficient of explanatory variables $i$ and $j$

$n$ - the number of correlation coefficients

The next step is the determination of the maximum integral capacity according to the following formula (3):

$$
H_{j}=\sum_{j, i=1}^{n} h_{j i}
$$

which corresponds to a combination of $\mathrm{C}=\{\mathbf{X 1}, \mathbf{X 5}\}=0.798$.

This means that the variables X1 (hazardous waste), and X5 (production efficiency), should enter into the assessment model of economic and environmental factors of the aggregates production.

Another value obtained is integral capacity determined for the variables $\mathbf{X 1}, \mathbf{X 3}, \mathbf{X 5}$, $\mathrm{C}=\{\mathrm{X} 1, \mathrm{X3}, \mathbf{X 5}\}=0.764$, i.e. the value obtained for hazardous waste energy consumption and production efficiency.

Inference carried out, while capacity indicators information have been used confirmed the results obtained by the graphs analysis. A significant correlation of mineral production with the mining efficiency ratio is generally understood. However, the environmental 
restrictions limit access to the deposits. One of the most restrictive forms of nature protection is European network of protected areas Natura 2000, which aims to preserve biodiversity by protecting entire ecosystems. Nearly $50 \%$ of area of the Subcarpathian province is environmentaly protected, and it is planned to increase the number of potential sites for habitat protection [3,6]. Theoretically, Natura 2000 does not oblige to stop the running production on restricted area, but in the case of exploited deposits, the need to refrain from exploitation can appear [1].

The analysis shows that not only the effectiveness of extraction, and the proper management (balancing area of land incorporated into the operation of aggregate with the surface of reclaimed land), but also the energy consumption and the volume of waste are significant factors conditioning the development of the open-pit mining industry.

In such circumstances it would be advisable to use in the production of construction aggregates energy from renewable sources.

\section{Recommendations by standards and specifications in the use of aggregates}

There are many documents and standards which define requirements of the use of aggregates in Poland. The most important are the technical requirements (WT4) published by the General Director for National Roads and Motorways (GDDKiA) [14], relating to the requirements of the materials used in road construction. These requirements systematise methods of production and use aggregates and asphalt mixtures (MMA), but some of the provisions included therein are ambiguous and raises serious concerns. For example, there is unclear procedure determining the parameter of sensitivity of MMA to water according to the standard PN-EN 1097-6 [15]. Unclear are also some provisions contained in WT-4 [14]. This is an important document ordering issues of mechanically stabilized substructures. However, the specifications written on this basis impose, for example, applying a mineral particle with sand equivalent index at least $40 \%$ or $45 \%$, even for the roads having the lowest traffic category. Polish Association of Aggregate Producers (PZPK) repeatedly requested to change this condition, having stressed that overestimated requirement restricted business competition [16]. Another issue is unnecessary limitation of the maximum particle size of the aggregates. Commonly used MMA allows the use of aggregate with particle size up to $16 \mathrm{~mm}$. In this way, one is not able to design a thicker layer, in which aggregate with particle size to $22 \mathrm{~mm}$ could be applied. This would rationalize the use of mineral resources, but the lack of adequate equipment for MMA testing laboratories.

In this situation, meeting the manufacturers production and expectations of customers deriving from the technical requirements and specifications become impossible.

As the result, there is a significant increase in production costs and the burden on the environment due to the need for additional storage of materials. It also affects the irrational use of non-renewable resources [16].

Referring to the requirements aggregates used to the concrete production, the specifications should be developed on the basis of currently recommended standard PNEN 206-1 [17]. It should be noted, that PN-EN 206-1 standard does not explain the water absorption requirements neither for aggregates nor for concrete. Using aggregate with high water absorption, it is necessary to calculate the quantity of effective water in the concrete mix, which means that one should be careful in the use of aggregates with water absorption greater than $3 \%$. The code does not specify the requirements for the mechanical properties of aggregates, as well.

In the case of specifications relating to non-cohesive soils, recommended to the construction of railway embankments and bridgeheads, the specifications define the basic 
requirements and related tests. This includes a strength parameters (internal friction angle), soil permeability, coefficient of uniformity, density index, organic content, $\mathrm{pH}$ index, and water content. These specifications recommend the implementation of backfill aggregate (e.g. gravely sands) with a specific grain size distribution, and some of them also provide the re-incorporation of soil from the excavation, conditioned by fulfillment of the above specification requirements and approval of Contract Engineer. As a rule, indigenous soil is not appropriate, but by addition of the particles of aggregate in the right proportion is able to meet the specifications. This is confirmed by laboratory tests carried out by the Department of Geodesy and Geotechnics by Rzeszow University of Technology in frame of the development of mixtures of indigenous soils with gravely sands and applications as backfill. This solution (mixing indigenous soil with aggregate) is considered effective in terms of both economic and environmental reasons. Both the contractor, saving on the cost of the purchase and transport of aggregate and masses of soil from the excavation, and the environment, gain a lot.

Specifications for aggregates used in bridge and railway construction are often too complex and required parameters overestimated due to the safety reasons. In developing of the requirements for aggregates used both for building construction and linear objects one should be guided primarily by rational use of non-renewable resources, rather than creating additional inconsistent requirements, which do not affect the safety and durability of engineering structures. Such an approach, however, requires full and continuous cooperation of the investor, designer and contractor.

\section{Conclusions}

One of the most restrictive forms of nature protection is the European network of protected areas by Natura 2000, which objective is to preserve biodiversity by protecting entire ecosystems. This plays a special role in the Subcarpathian region where, as it has been mentioned in the work, the areas covered by such protection constitute almost half of the province. When analyzing the environmental issues discussed on the example of the largest aggregate manufacturer in the Subcarpathian province, one may formulate the following conclusions:

-minimizing the influence of the environmental impact of the production of construction aggregates may be achieved primarily by implementation of modern technology and modernization of the existing mining equipment, which provide for more rational use of natural resources, while reducing significantly the emissions of pollutants into the environment.

- increase of the protected areas prevents or even restricts access to natural resources (by reducing production of aggregates), so the environment protection rises to the primary factor limiting the development of the natural aggregates production.

- in developing the requirements for aggregates used both for building of various types of construction and linear objects one should be guided primarily by rational use of nonrenewable resources, rather than creation of additional requirements, which do not affect the safety and durability of engineering structures.

- based upon the analysis which had been carried out by the index information capacity method it may be concluded that the production volume depends on hazardous waste, the efficiency ratio of production and electric energy consumption.

- it is desirable then to use in the production of construction aggregate energy from renewable sources.

- noticeable decreasing trend of hazardous waste is only apparent, because by outsourcing of services outside the company, the waste associated with contract execution, by law, belong to the contractor. 
- rational requirements and recommendations specified by standards and specifications for the use of aggregates, would guarantee the reasonable use of non-renewable resources.

On the basis of the analysis performed in the work using the Helwig and Bartosiewicz method, it can be concluded that renewable energy sources can be successfully applied at the production of aggregates. For example, small hydroelectric power stations can be effectively exploited at the manufacturing process of aggregates to decrease the costs of energy.

\section{References}

1. G. Bajorek, M. Kiernia-Hnat, I. Skrzypczak, Works of Institute of Ceramics and Building Materials, 5, 9 (2012)

2. B. Berge, The Ecology of Building, Materials, Oxford Architectural Press (2001)

3. West T.R., Kyuho Cho, IAEG, 692 (2006)

4. S. W. Danielsen, E. Kuznetsova, Engineering Geology for Society and Territory,_44, 5 (2014)

5. R. Poulin, R. C. Pakalnis, K. Sinding, Environmental Geology, 23, 3, (1994)

6. http://www.stat.gov.pl/cps/rde/xbcr/gus/PUBL_rs_rocznik_stat_wojew.pdf (2015)

7. First Forum of Aggregates Producers. Warsaw (in Polish) (2009)

8. Kruszgeo: Environmental Declaration, Rzeszow (in Polish) (2006-2015)

9. J. Dziechciarz, Econometrics, Publisher University of Economics in Wroclaw (in Polish) (2002)

10. Z. Hellwig, in Z. Gostkowski (ed.), Toward a system of quantitative indicators of components of human resources development, UNESCO (1968)

11. P. Kowalik, 2, Publisher of University of Business, Kielce (in Polish) (2011)

12. P. Kowalik, Monographs of Lodz University of Technology, Publisher of Lodz University of Technology (in Polish) (2014)

13. F.S. Hillier, G.J. Lieberman, Introduction to Operations Research, 4th Edition, McGraw Hill, New York (1986)

14. Technical Guidelines 4 WT-4 (in Polish)

15. PN-EN 1097-6:2002/AC:2004 Research of mechanical and physical properties of aggregates. Part 6: Determination of grain density and absorption

16. http://inframedia.pl/article_advances/category/kruszywa/1/kruszywa_podaz_a_popyt/1

17. PN-EN 206-1: 2014 Concrete. Part 1: Requirements, properties, production and conformity 